\title{
The current status of community drug testing via the analysis of drugs and drug metabolites in sewage
}

\author{
Malcolm J. Reid, Christopher Harman, Merete Grung and Kevin V. Thomas \\ Norwegian Institute for Water Research (NIVA), Oslo, Norway \\ Correspondence: Kevin Thomas, NIVA, Gaustadalléen 21, NO-0349 Oslo, Norway \\ E-mail: kth@niva.no
}

\begin{abstract}
Over the past few years the analysis of drug residues in sewage has been promoted as a means of estimating the level of drug use in communities. Measured drug residue concentrations in the sewage are used to determine the load (total mass) of the drug being used by the entire community. Knowledge of the size or population of the community then allows for the calculation of drug-use relative to population (typically drug-mass/day/1000 inhabitants) which facilitates comparisons between differing communities or populations. Studies have been performed in many European countries, including Norway, as well as in the US and Australia. The approach has successfully estimated the use of cocaine, amphetamine, methamphetamine, MDMA, cannabis, nicotine and alcohol. The analysis of biomarkers of drug use in sewage has great potential to support and complement existing techniques for estimating levels of drug use, and as such has been identified as a promising development by the European Monitoring Centre for Drugs and Drug Addiction (EMCDDA; www.emcdda.europa.eu/wastewater-analysis). The approach is not without its challenges, and ongoing collaboration across Europe aims at agreeing upon best-practice and harmonising the methods being used. In Norway development is being performed through the NFR RUSMIDDEL funded DrugMon (www.niva.no/drugmon) project that has led to the development of many new techniques, significantly improved our understanding of the uncertainties associated with the approach and allowed the coordination of Europe wide collaboration which has included all important intercalibration exercises. Application of the technique can provide evidence-based and real-time estimates of collective drug use with the resulting data used to improve the much needed estimates of drug use and dependency.
\end{abstract}

\section{INTRODUCTION}

Measuring the extent of drug use in society is important in order to support and develop an effective drug policy and also monitor the effectiveness of existing policies. Over the past few years a new technique, based on the analysis of urinary drug biomarkers in sewage, has been developed to complement existing epidemiological studies. This approach has been referred to as 'sewage epidemiology' and 'Forensic Epidemiology Using Drugs in Sewage' (FEUDS; Daughton et al., 2011). The technique, which is effectively a communityscale drug test, has thus far been used in the estimation of drug use by specific populations (i.e. cities) in Europe, North America and Australia (Table 1).

In order to determine the scale of drug use by a community it is first necessary to have access to the sewer network that serves the community under study. Discrete sewage samples representative of a particular period of time (i.e. 1 day) are typically collected at the point of entry into sewage treatment plant (STP) using an automated sampling device. The collected samples are then quantitatively analysed for the presence of targeted drug residues to determine their concentration in the sample. The concentration of the drug residue of interest is then subsequently used to calculate the total amount (i.e. daily load) of drug residue that has passed through the sewer system over the sampling period. This is possible by multiplying the drug residue con- centration with the flow of effluent past the sampling point. The daily drug residue load is then used to backcalculate the amount of a particular drug used by a population by using the available pharmacokinetic data which provides the amount (or percent) of the specific drug residue that is typically released in a person's urine following administration of the drug. Estimates are also required on the sizes of the population tested that are available from a number of different sources that will be discussed in-depth later. This paper will critically review the current status of estimating community drug use through sewage analysis and discuss the future potential of the technique.

\section{SAMPLING AND ANALYSIS}

\section{Overview of sampling considerations and need for characterising system}

The major assumption with studies examining drug use that are based on measurements in sewage, is that a sample of wastewater is representative of a combined (pooled) urine sample of the entire population in the catchment (or study) area. Sewage samples must therefore be collected from a point in the sewage system that processes sewage from all members of the study population. As most cities have more than one sewage treatment plant then unless the demographics or drug use statistics of the entire city are identical, then samples must be collected from every area in the sewage 
network, in order to provide a complete analysis (see later for an example of differences within a city).

Another important point for consideration is that the flow of sewage is uneven over the course of; a single day, a week and seasonally, so this must also be taken into account. Flow generally increases during the day when the population is awake, and is often seen to decrease at night when the population is sleeping. Weekly variation in flow, meanwhile, is most often related to commuter activity and/or major population changes related to holidays and weekends where people exit the catchment area. Seasonal changes may be related to precipitation patterns, where drainage water also forms part of the flow through the system.

The mass of drug (or the mass of the chosen urinary biomarker) in the sewage is also observed to vary throughout the day and on different days of the week. This is both a result of changes in the total flow of sewage, but also a result of usage patterns and metabolism of the different drugs. Cocaine and alcohol, for example, are mostly used/consumed in the evening hours and at the weekends (Reid et al., 2011a), so spikes in the amount of cocaine and alcohol related metabolites are subsequently observed at times that correspond with this usage pattern.

The daily total drug mass from a population or study catchment is calculated from measurements of sewage concentrations which are multiplied by the total volume of wastewater in the day, taking into account the population and excretion rates. Wastewater samples must therefore be collected in such a way that they accurately represent the total volume of sewage from the entire day irrespective of diurnal patterns (sleep/ wake cycles), commuter behaviour or population changes, or drug use patterns (weekend use only, or habitual). The generally accepted method of sample collection is flow proportional sampling, although most of the studies available in the literature use time proportional sampling for convenience (van Nuijs et al., 2011a).

The stability of the drugs, their metabolites and/or the chosen biomarker is also extremely important. The average time taken between the human bladder and sample collection is generally of the order of a number of hours due to the large volumes and long distances in the sewage network. Failure to take these factors into account can lead to incorrect conclusions being drawn from unrepresentative samples and thus the sampling regime and frequency are critical, and may be specific to the study system (Ort et al., 2010). Published data suggest that most of the illicit drug biomarkers typically used are relatively stable over $24 \mathrm{~h}$ (Castiglioni et al., 2006), the one exception being cocaine and its metabolite benzoylecognine. It has been reported that the concentration of cocaine can be reduced by between 7 and $40 \%$ over $24 \mathrm{~h}$, resulting in increased benzoylecognine concentrations (Baker and Kasprzyk-Hordern, 2011). This is an important consideration for composite sampling and stabilisation of the sample through using refrigeration and acidification ( $\mathrm{pH} 2)$ is recommended.

Decreasing the sampling interval clearly increases the resolution, allowing diurnal trends to be established, for example to show increased use of cocaine at the weekends (Reid et al., 2011). However this quickly produces a large number of samples, in excess of 100 during the course of one month, in the above example. This is clearly not financially efficient due to both man hour, and analysis costs. This is especially the case if long-term trends or widespread coverage are required. Even taking a single daily composite sample over a period of months (van Nuijs, 2011b) quickly becomes challenging, and questions remain about how representative it is due to the known potential for fluctuations in concentrations (Ort et al., 2010). Thus the wider application of an approach using discrete water samples (generally using automatic equipment), especially where long term trends are required, is not feasible due to the associated costs and also for more practical reasons, not least the need for a suitably sized sampling point with power available (Harman et al., 2011a). In this regard passive sampling devices (PSDs) may have much to offer.

\section{Passive sampling and its potential}

Passive samplers may be described as "human-made devices where sample collection and residue extraction occur simultaneously in a completely passive manner" (Huckins et al., 2006). The principle of these techniques is the placement of a device in the water to be sampled, for a set period of time, typically a few weeks, where it is left to accumulate target compounds. Such devices usually consist of a semi-permeable or partly porous membrane and a receiving phase (such as a sorbent) with affinity for the target compounds. These configurations can often be changed in order to meet specific sampling goals/compounds. The advantages of PSDs over traditional bottle and auto-sampling include; lower detection limits, measurement of only the freely dissolved fraction and samples which are integrated over time, thus compensating for fluctuating concentrations. For these reasons, a variety of different PSDs have been applied to a wide range of target compounds and sampling scenarios within the environmental sciences (Vrana et al., 2005). Additionally as compounds are not just sampled but also extracted in situ, their stability is assumed to be greater than if left in water samples. This in turn means that they may also be extracted retrospectively to look for emerging compounds of interest more conveniently than trying to stabilise and store many large volume water samples.

In theory passive samplers are also flow integrative to an extent. This is because as water turbulences increase the thickness of the water boundary layer, present at the surface of the membrane is reduced. This layer of static water is often the biggest hindrance to uptake and thus its reduction results in enhanced uptake. In the case of sewage epidemiology it is difficult to 
know how an increase in the total volume of water going through the sewage system being tested is represented by faster flow past the sampler surface and in turn higher uptake rates for specific chemicals. Such relationships are likely to be specific to each exposure scenario. Thus, whilst passive sampling may overcome fluctuating concentrations and practical issues, they do not necessarily completely solve the problem of adjusting the sample for changes in the volume through the system.

Thus this is one of the weaknesses with the currently available passive samplers suitable for sampling polar compounds, the lack of an exposure correction method, which may adjust reference sampling rates to the specific exposure. This problem has been elegantly overcome for hydrophobic passive samplers (used for sampling more traditional pollutants such as PCBs) by the addition of performance reference compounds (PRCs) (Booij et al. 1998). These 'labelled' compounds are spiked into samplers prior to deployment and modelling their dissipation in situ, allows the provision of both compound and exposure specific sampling rates for each target compound (Huckins et al. 2006). Whilst some progress has been made in applying a PRC approach to polar passive samplers (Mazzella et al. 2010), it must be cautioned that laboratory derived sampling rates, can only currently give an estimation of exposure water concentrations. Calibration in situ is also possible and will give more accurate results, as exposure conditions and matrix effects will be similar. Although such an approach is both time-consuming and expensive, once the sampling rates are known, then that location may be continuously sampled over a much longer time period. For example Harman et al. (2011) recently measured drug use of Western Oslo and surrounding districts for a whole year, from just 72 PSD analyses.

Despite the challenges when using PSDs, they are likely to play a critical role in the development of sewage epidemiology and its wider application. This is especially the case when long term trend data is required and the associated costs and practicality of using autosampling equipment are prohibitory.

\section{Overview of analytical methods used}

Sensitivity requirements in sewage analysis are generally more demanding than those of typical forensic toxicology or clinical studies due to the large dilution of the urine in a sewage system. Analyte concentrations are commonly at the low $\mathrm{ng} / \mathrm{L}$ level because human urine is often less than $1 \%$ of the total volume of wastewater in a combined sewage system. The remaining volume is made up of water (showers, toilets, washing machines etc), rain, snow-melt and industrial waste. Sample clean-up and pre-concentration via Solid Phase Extraction (SPE), and subsequent sample analysis via liquid chromatography coupled with tandem mass spectrometry (LC-MS/MS) provide sufficient specificity and sensitivity so are subsequently the most com- monly used techniques in this field. Sewage samples (typically with volume of between 50 and $1000 \mathrm{~mL}$ ) are loaded on the SPE cartridges (reverse phase C18 and/ or cation exchange) and washed to remove interfering matrix before the analytes are eluted in a small volume of organic solvent for analysis. Deuterium-labelled reference standards are recommended for each analyte in order to eliminate effects from the sample matrix. Final sample volumes of $100-1000 \mu \mathrm{L}$ (reduced from a starting sewage volume of $50-1000 \mathrm{~mL}$ ) give a sample pre-concentration factor of 50-10 000 which improves the detection limits appreciably.

The analyte of choice in sewage studies is generally the primary urinary metabolite of the drug of interest. Benzoylecgonine, for example, is the primary urinary metabolite of cocaine representing $15-55 \%$ of the original dose in urine, and it is this compound that is most commonly used for the estimation of cocaine use by sewage analysis. Care must be taken in the choice of analyte however because many illegal drugs and pharmaceuticals have very similar chemical structures and share common moieties. The metabolism and excretion of the various illegal drugs (and the various pharmaceuticals) therefore follow similar pathways and result in identical metabolites. Heroin, for example, is rapidly metabolised to morphine but estimates of the community-wide use of heroin cannot be derived from sewage measurements of this metabolite because this is not distinguishable from the legal use of morphine and morphine-related pharmaceuticals. One option is to use 6-monoacetylmorphine (6-MAM), a minor metabolite of heroin, as a sewage biomarker (van Nuijs et al., 2009), however even when detected in sewage the highly variable rate of excretion make estimating heroin use very difficult. 6-MAM has never been detected in sewage samples collected from Norway, suggesting that there are insufficient heroin users present for 6-MAM to be detected.

Table 1 includes a review of some of the most recent sewage studies into drug use. The table provides detail on the $\operatorname{drug}(\mathrm{s})$ investigated in each case, the target analyte(s), and the countries in which the studies have been conducted.

\section{Need for intercalibration}

As with any emerging field of research, there is a great deal of work that is required before routine estimates of drug-use from sewage analysis can be realised. Analytical methods have been independently validated in a number of laboratories across Europe, Australia and America, but the need for inter-laboratory calibration is imperative. Sewage is a complex mixture of chemical and biological elements that are unique to each and every wastewater network. Differences in the industrial activity in two study areas, for example, can result in a significantly different sewage composition such that one analytical method may not be suitable for both locations. 
Table 1. The analysis of community-wide drug consumption by detection and quantification of specific urinary excretion products in sewage. Details of recent studies - pairing the drug of abuse with the sewage analyte and a list of countries in which such studies have been performed since 2009 . (References in brackets).

\begin{tabular}{|c|c|c|}
\hline Drug of abuse & Sewage analyte & Study countries \\
\hline Alcohol & Ethylsulfate (16) & Norway (16) \\
\hline \multirow[t]{9}{*}{ Cocaine } & Benzoylecgonine (1-15) & Norway $(11,15)$ \\
\hline & Ecgonine Methylester $(6,7,12,14)$ & Belgium $(6,7,14)$ \\
\hline & Cocaine $(1,2,4-13,15)$ & Spain $(2,9,13)$ \\
\hline & Cocaethylene $(2,9,11,13)$ & Australia (12) \\
\hline & & France (10) \\
\hline & & Switzerland (8) \\
\hline & & Italy $(1,5)$ \\
\hline & & UK (4) \\
\hline & & USA (3) \\
\hline \multirow[t]{8}{*}{ Amphetamine } & Amphetamine $(1,2,4,7-14)$ & Italy (1) \\
\hline & & Spain $(2,9,13)$ \\
\hline & & UK (4) \\
\hline & & Belgium $(7,14)$ \\
\hline & & Switzerland (8) \\
\hline & & France (10) \\
\hline & & Norway (11) \\
\hline & & Australia (12) \\
\hline \multirow{7}{*}{$\begin{array}{l}\text { Methampheta- } \\
\text { mine }\end{array}$} & Methamphetamine & Italy (1) \\
\hline & $(1,2,3,7-9,11-15)$ & Spain $(2,9,13)$ \\
\hline & & USA (3) \\
\hline & & Belgium $(7,14)$ \\
\hline & & Switzerland (8) \\
\hline & & Norway $(11,15)$ \\
\hline & & Australia (12) \\
\hline \multirow[t]{4}{*}{ Cannabis } & THC-COOH $(1,2,8,9,12,13)$ & Italy (1) \\
\hline & THC $(9,12,13)$ & Spain $(2,9,13)$ \\
\hline & & Switzerland (8) \\
\hline & & Australia (12) \\
\hline \multirow[t]{8}{*}{ Ecstasy } & MDMA $(1-3,7-13)$ & Italy (1) \\
\hline & $\operatorname{MDEA}(2,9,12)$ & Spain $(2,9,13)$ \\
\hline & $\operatorname{MDA}(2,9,12)$ & USA (3) \\
\hline & & Belgium (7) \\
\hline & & Switzerland (8) \\
\hline & & France (10) \\
\hline & & Norway (11) \\
\hline & & Australia (12) \\
\hline \multirow[t]{6}{*}{ Opioids } & Morphine $(1,5,8,9,11-13)$ & Italy $(1,5)$ \\
\hline & Codeine $(8,9,12)$ & Belgium $(7,14)$ \\
\hline & 6-MAM $(7,13,14)$ & Switzerland (8) \\
\hline & $\operatorname{EDDP}(7,8,12,13,14)$ & Spain $(9,13)$ \\
\hline & & Norway (11) \\
\hline & & Australia (12) \\
\hline
\end{tabular}

1. Zuccato et al., 2008; 2. Bijlsma et al., 2009; 3. Banta-Green et al., 2009; 4. Kasprzyk-Hordern et al., 2009; 5. Mari et al., 2009; 6. van Nuijs et al., 2009; 7. van Nuijs et al., 2009; 8. Berset et al., 2010; 9. González-Marino et al., 2010; 10. Karolak et al., 2010;

11. Harman et al., 2011; 12. Lai et al. 2011; 13. Postigo et al., 2011; 14. van Nuijs et al., 2011; 15. Reid et al., 2011; 16. Reid et al., 2011.

\section{CAlCUlating AND REPORTING USE DATA}

Quantitative analysis of sewage provides only part of the data required to estimate the amount of a drug being used. Estimating the amount of a drug that has been used by a population requires the drug load to be calculated by multiplying the sewage effluent flow with the concentrations quantified in the sample. This will typically represent the drug load over a given period of time (corresponding to the sample collected; i.e. $\mathrm{g}$ /day). The next step is to normalise these data to the population. This is an important step that can strongly influence the final result and therefore it is important to understand factors that may influence the population being served by the study population. For example, the inter-catchment transient movement of people may significantly influence the number of people present in the catchment area at the time of sampling. Estimating the size of the population that has contributed to an effluent sample requires prior knowledge of the type of effluent received by the STP and the movement of people. Systems where there is known to be little population change combined with good census data and an understanding of the STP catchment may mean that census data may provide the best estimates of population. However, in other instances it may be necessary to estimate the population from biological- or chemicaloxygen demand (BOD or COD), phosphorus or nitrogen data using published methods (Andreottola et al., 1994; Garnier et al., 2006). In countries where there are good records on the annual use of human pharmaceuticals then the co-analysis of human pharmaceuticals in the collected samples can provide an estimation of the population being tested (Reid et al., 2011a; Harman et al., 2011; Lai et al., 2011). To date atenolol, metoprolol and cetirizine have been used in this capacity. Including the metabolites of such pharmaceutical markers (i.e. metoprolol acid) is also important as it provides information on the amount of the pharmaceutical actually consumed (Reid et al., 2011a). Due to the importance of estimating the correct size of the population in this normalisation step it is recommended to use as many methods as possible for comparison before deciding on the best estimate.

To estimate the amount of a drug used there is a need to consider how much of the chosen drug biomarker is excreted in urine. Here lies one of the greatest challenges that the technique faces sine there are few quantitative pharmacokinetic studies for illicit drugs and high variability in the reported metabolite excretion profiles. Castiglioni et al. (2011) recently compared the metabolite excretion patterns of cocaine in urine and sewage effluent and found that they compared favourably, with benzoylecognine being confirmed as the most suitable cocaine metabolite for estimating cocaine use. In backestimating the amount of cocaine consumed from benzoylecognine it has recently been proposed that a median excretion rate of $38 \%$ of the consumed dose, with a correction factor of 2.77 , be used for estimating cocaine consumption (Castiglioni, Pers. comm.) This value is the median of all the public domain pharmacokinetic data available. At the present time it is difficult to estimate the use of the other drugs that are typically determined in sewage. This is primarily due to the absence of sound pharmacokinetic data. 


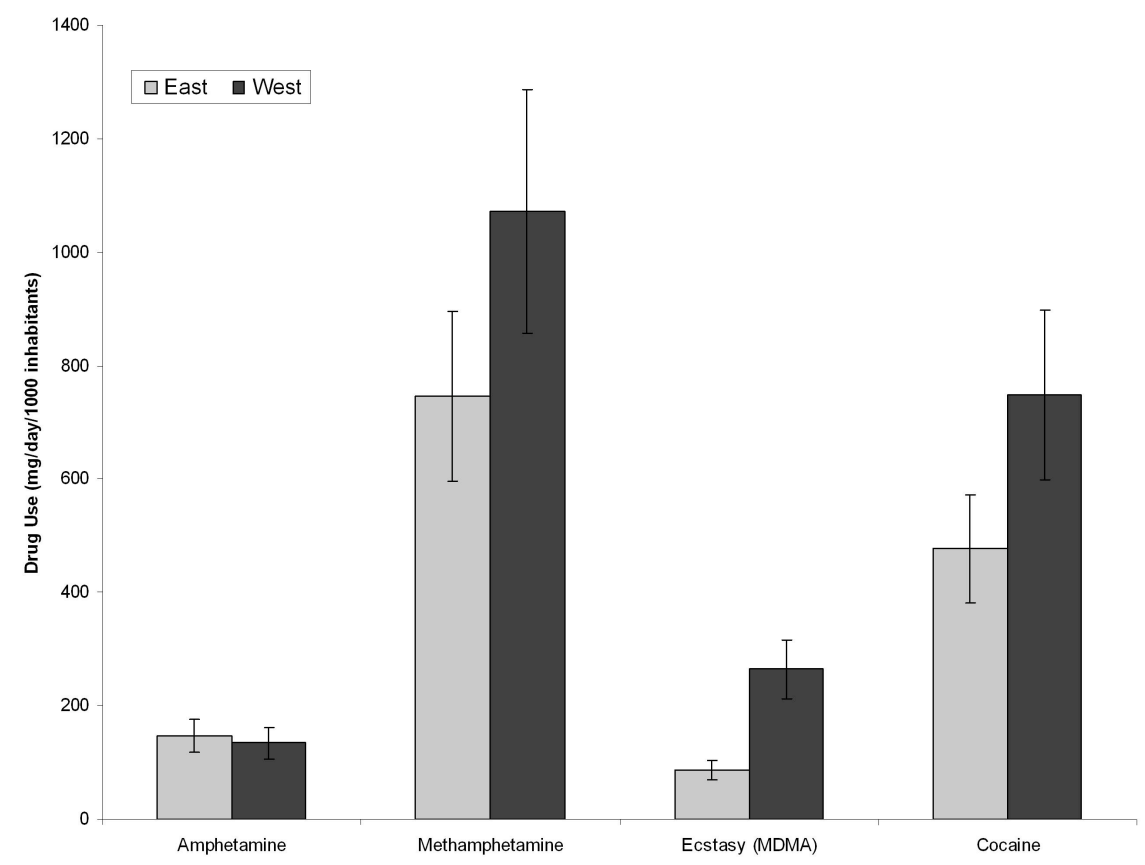

Figure 1. Comparison of amphetamine, methamphetamine, MDMA and cocaine use between East and West Oslo, 2009. Cocaine was measured as benzoylecgonine and back-calculated using an excretion rate of $35 \%$ excretion. Methamphetamine was measured directly and calculated using an excretion factor of $40 \%$ excretion. Amphetamine was measured directly, use estimated using a $35 \%$ excretion rate and then corrected for the $10 \%$ excretion of methamphetamine dose that appears as amphetamine. MDMA was measured directly and use estimated using a $15 \%$ excretion rate. The error bars are $20 \%$ RSD (Lai et al., 2011) representing uncertainty in excretion rates.

\section{THE NEED FOR A COMMON GUIDANCE DOCUMENT}

It is clear that estimating drug use through the analysis of sewage offers considerable promise. For the approach to be used widely for comparative spatial and temporal studies there is a requirement to understand and reduce the uncertainty associated with different steps of the process. One way to achieve this is to establish best practice and provide this to practitioners in the form of a guidance document. Such a guidance document will have to cover all aspects of the process and be based upon the existing knowledge from the expert that has helped develop the approach thus far. The establishment of a Europe wide demonstration project involving experts from a number of different areas and the establishment of a working group of key scientists would be an important step in sewage analysis being applied as an accepted approach in estimating the prevalence of drug use. To this end a number of significant steps have already been taken. The EMCDDA have played an important role in this respect with two expert group meetings being held. The first evaluated the potential and limitations of the approach that resulted in the publication of a report entitled "Assessing illicit drugs in wastewater" (EMCDDA, 2008), whilst the second reviewed the state of the art and what further developments are required (www.emcdda.europa.eu/ wastewater-analysis). In addition to these meetings, NIVA and the Mario Negri Institute for Pharmacological Research (Italy) in December 2010 initiated a
Europe wide collaboration where most of the institutes with an interest in this emerging field came together to perform a Europe wide study where the illicit drug use of 19 cities was determined over a one week in March 2011. This resulted in a common approach being agreed upon along with an evaluation of the uncertainty associated with the sampling performed at each location. This common approach was successfully used to determine the use of cocaine and the loads associated with amphetamine, methamphetamine, MDMA and cannabis for $14.5 \times 10^{6}$ people and will likely form the basis of any future guidance document. To develop this methodology further there will be a need for a coordinated approach in undertaking research to better understand the uncertainties associated with the different steps of the process as well as demonstrating the suitability of the approach for the international monitoring of drug use.

\section{REAL-TIME AND QUANTITATIVE ANALYSIS}

As has been highlighted above the sewage biomarker estimation of drug use patterns can provide real-time and quantitative data on drug use within a discrete community. To illustrate this three examples are provided; the first comparing differences between drug flow between east and west Oslo (Figure 1), the second comparing differences in cocaine use during the $17^{\text {th }}$ May, national day celebrations (Figure 2), and a regular period and the third comparing differences in drug loads at a Norwegian ski resort during a regular week- 


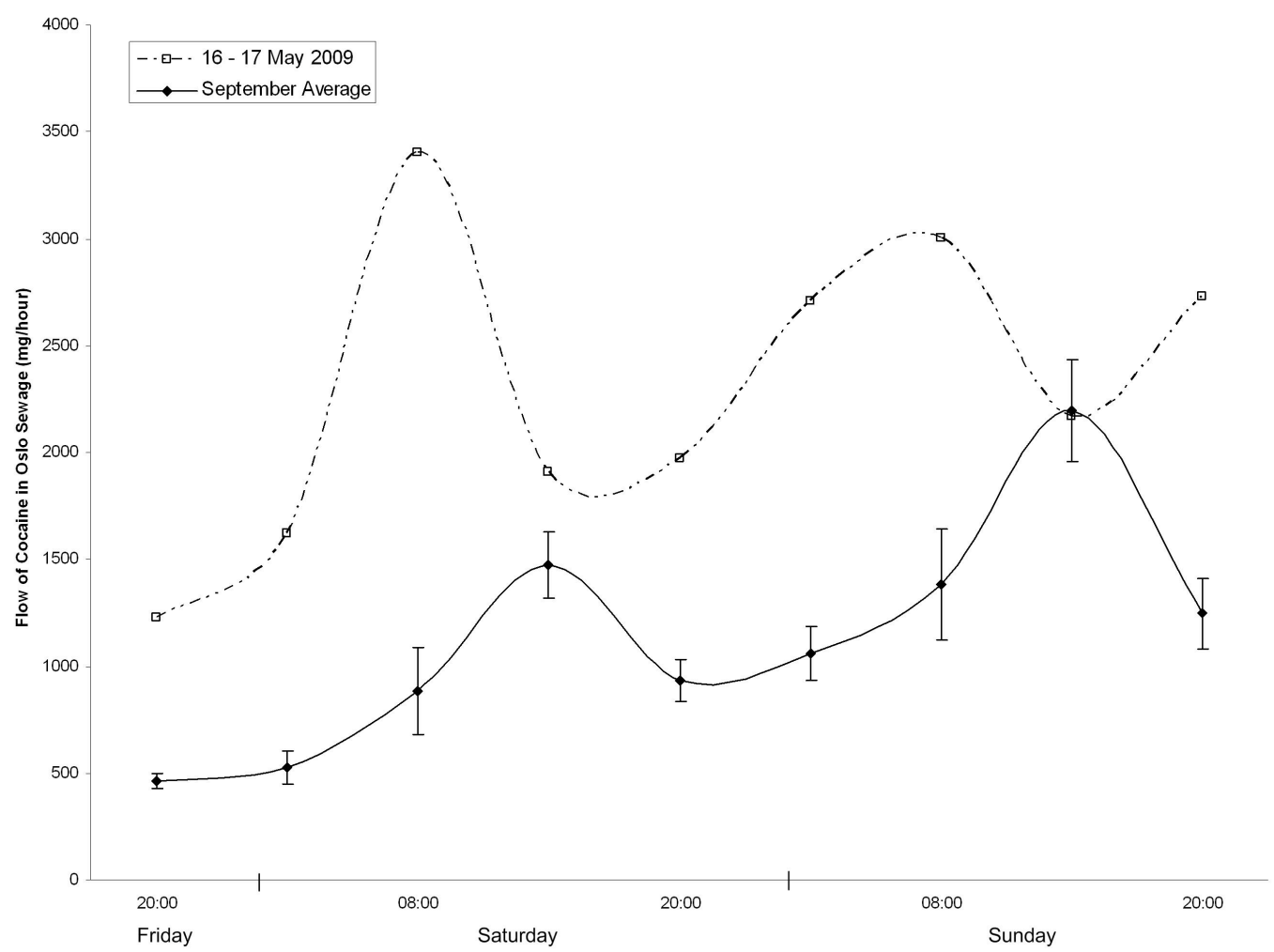

Figure 2. Cocaine flow in sewage from Oslo on a regular weekend in 2009 compared to the period covering national day celebrations (15th May $(8 \mathrm{pm})$ to 17 May $(8 \mathrm{pm}))$. September data show the average $(\mathrm{n}=4)$ from the 4 consecutive weekends in September 2009.

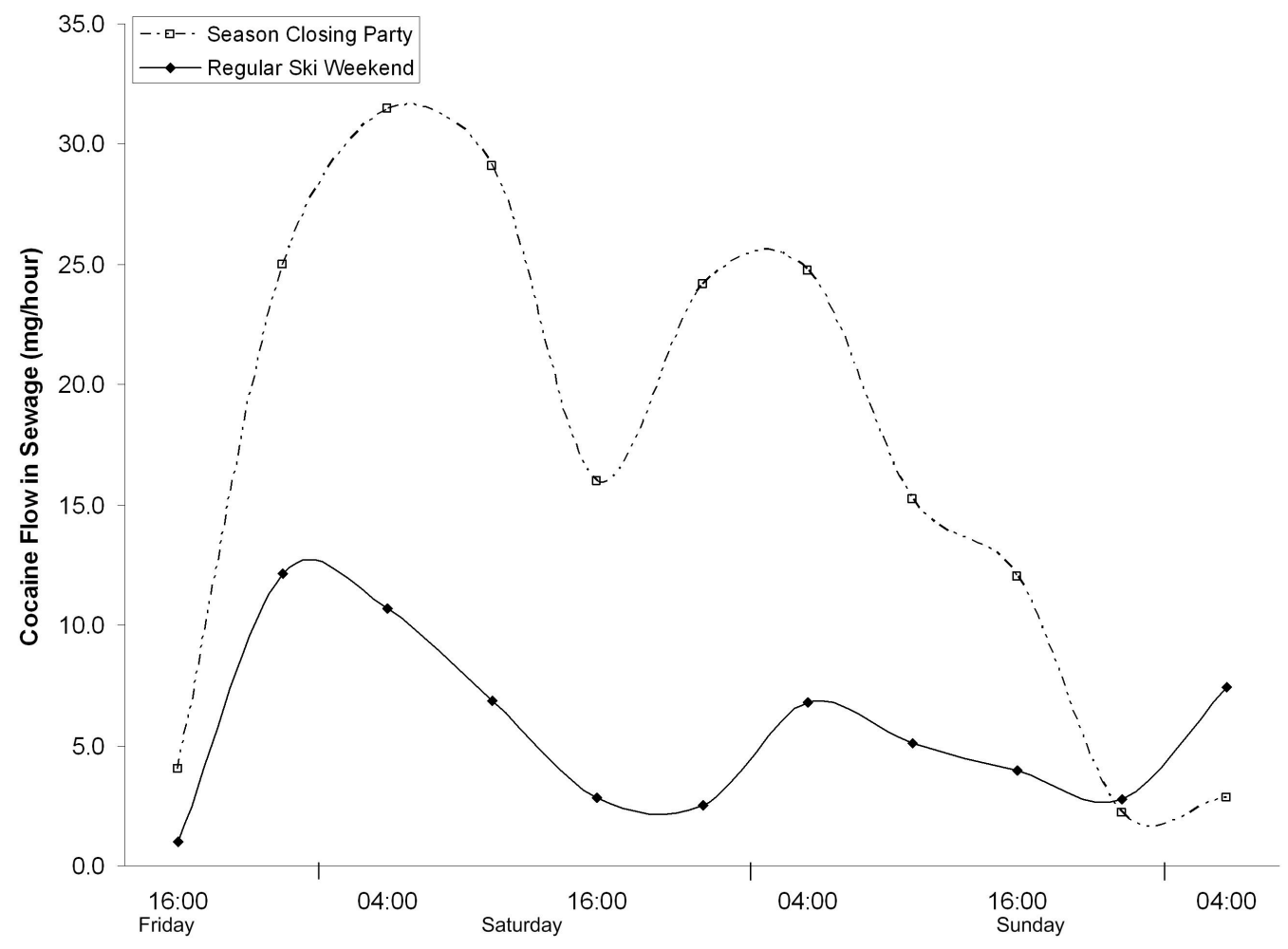

Figure 3. Cocaine flow in sewage from a Norwegian ski resort over two weekends showing the differences between a regular weekend and the closing party weekend. Samples collected 26th - 29th March 2010 (normal weekend) and 30th Apr - 3rd May 2010 (party weekend). 
end and the closing festival weekend (Figure 3). The first example (Figure 1) shows how the technique can quantify the differences in drug use between two areas of the same city. It is evident from the data that there is increased use of methamphetamine, MDMA and cocaine in the area served by VEAS STP than that served by Bekkelaget STP. The second example (Figure 2) shows increased cocaine flow in Oslo on the weekend of the national day compared with a regular weekend. The data also show a peak in the flow at an earlier time than typically seen for the same area indicating that the peak in use was earlier than typically recorded. Similar data are also presented for a Norwegian ski resort where the flow of cocaine during a specific party even is greater than that typically observed (Figure 3) suggesting increased use. It should be noted that these data are not normalised to the number of people and as such probably reflect an increase in the number of cocaine users in the area served by the STP at the time of the event.

\section{COMPARISON OF SEWAGE ANALYSIS WITH CONVENTIONAL APPROACHES TO MEASURING DRUG USE}

A description of the methods used for estimating the prevalence of drug use has been published by Wiessing et al. (2008). There are principally two methods; direct estimation through general population surveys, and indirect estimation that are based on extrapolating from the observed parts of the target group to be estimated (e.g. surveys among specific populations of drug users, at parties etc.). Other information about drug use can be obtained, e.g. from registration systems at emergency care units of hospitals, at institutes for addiction care, seizures of drugs by the police, the number of deaths associated with use of drugs, the number of drivers under the influence of drugs. The major limitations with population surveys are that they are costly and time consuming. Also, there will always be an unquantifiable uncertainty about the reliability of the results, which is even more so for the indirect methods of assessing drug use. The temporal trend of changing drug use patterns in a community as well as drugs with low or specific prevalence will also be difficult to assess by the use of these methods.

As such, analyses of wastewater for drugs offer a complementary approach to traditional methods of estimating community drug use. The potential for using sewage analysis was highlighted by Wiessing et al. (2008), and more recently by Brunt (2011). There are several strengths to this approach, and comprise amongst others:

- Objectivity of the method

- The whole population in a specific region is sampled

- Rapid temporal and spatial data collection

- The method has the potential to be compatible between different countries/regions

- Relatively cost- and time-effective
Sewage analysis will provide information where other methods are limited, and in theory measuring the effectiveness of a drug intervention campaign can be envisaged. In a study performed in Oslo, the quantity of ethyl sulphate, a metabolite of ethanol, passing through the sewage system was able to give an accurate estimate of the actual alcohol consumption by the population (Reid et al., 2011). Additional information about the ethanol consumption pattern in Oslo was provided by the study. Wastewater analysis of the antihistamine cetirizine (Harman et al., 2011) showed a clear increase in use during the summer months as expected. The back calculation of the yearly dosage yielded very similar results to that registered in the Norwegian prescription database. The two studies show that the results can be used for back-calculation of the amount of drugs used by the population as a whole. Also temporal trends in use can be seen quite easily, as the increased amount of ecstasy during May (Harman et al., 2011), and the fact that around 60\% of ethanol is consumed during weekends in Oslo (Reid et al., 2011).

A recent evaluation of the uncertainty associated with the analysis of sewage to estimate drug use by Lai et al. (2011) suggests that when best sampling and analysis practices are employed the uncertainty lies between 20 to $30 \%$ (relative standard deviation). This evaluation however did not include degradation of the target biomarkers in the sewer system between the point of release and sampling.

Where sewage analysis is limited is that information about the drug users and their drug use is lacking. Such information can only be obtained from population surveys. Therefore, wastewater analysis and population surveys complement each other, each giving a different aspect of drug use in a society. It is clear that the complementary use of different techniques for the same location will lead to an improved and balanced assessment of the drug use and dependence.

\section{FUTURE POSSIBILITIES}

Estimating community drug use through the analysis of sewage for the biomarkers of illicit drugs has in effect created a new and exciting area of research. The law enforcement and drug related agencies that make use of these data can influence where the future developments and advancements are made. It is generally accepted that there is insufficient information on illicit drug markets. Continual monitoring using the passive sampling approach outlined earlier can be used to monitor the long-term flow of specific drugs through the sewer network serving a population. It is even conceivable that on-line monitors could be placed at the inlet of STPs and provides online real-time data on the flow of illicit drugs through a city. Another area that has been suggested as a further application of the approach is to screen samples for the presence of new and emerging drugs in order to provide up to date 
information on new trends and an early warning on the use of new substances. This would of course require a sufficient number of individuals to be using any new substance in sufficient quantities for it to be detected for the approach to work.

The sewage analysis approach is not restricted to illicit drugs, with for example, alcohol and tobacco use also being estimated from the measurement of specific urinary biomarkers (Reid et al., 2011). Other urinary biomarkers, of disease and health related factors, may be one area that would provide information on the health of an entire population. Thomas and Reid (2011) recently suggested that comparing the 'sewage biomarker fingerprint' of different communities may be a valuable tool for public health agencies to rapidly assess the overall health of a particular community. Such a development would of course require a significant amount of research before it can be realised but the potential is clear.

\section{CONCLUSIONS}

The estimation of community drug use through sewage testing has clear potential in providing quantitative and real-time data for specific study populations. For the conclusions of sewage analysis estimations to be robust and representative of illicit drug used there is a need to understand the uncertainty associated with all steps of the process. The approach is particularly suited towards inter-population comparisons; however such comparisons should be performed with a thorough characterisation of the uncertainties that may influence the results (i.e. transient movement of people, sampling, analysis and factors affecting metabolism). A guidance document, associated quality assurance/control criteria will be required for the effective inter-state comparison of results. The wider application of sewage analysis for the estimation of drug use will be a valuable addition to the data gathering tools currently available to epidemiologists in improving the quality and coverage of data on drug use and dependence.

\section{REFERENCES}

Andreottola G, Bonomo L, Poggiali L, Zaffaroni C. A methodology for the estimation of unit nutrient and organic loads from domestic and non-domestic sources. Eur Water Pollut Control 1994; 4 (6): 13-19.

Baker DR, Kasprzyk-Hordern B. Critical evaluation of methodology commonly used in sample collection, storage and preparation for the analysis of pharmaceuticals and illicit drugs in surface water and wastewater by solid phase extraction and liquid chromatography-mass spectrometry. J Chromatogr A 2011; 1218: 8036-8059.

Banta-Green CJ, Field JA, Chiaia AC, Sudakin DL, Power L, de Montigny L. The spatial epidemiology of cocaine, methamphetamine and 3,4-methylenedioxymethamphetamine (MDMA) use: a demonstration using a population measure of community drug load derived from municipal wastewater. Addiction 2009; 104: 1874-1880.

Berset JD, Brenneisen R, Mathieu C. Analysis of llicit and illicit drugs in waste, surface and lake water samples using large volume direct injection high performance liquid chromatography-electrospray tandem mass spectrometry (HPLC-MS/MS). Chemosphere 2010; 87 (9): 856-866.

Bijlsma L, Sancho JV, Pitarch E, Ibáñez M, Hernández F. Simultaneous ultra-high-pressure liquid chromatographytandem mass spectrometry determination of amphetamine and amphetamine-like stimulants, cocaine and its metabolites, and a cannabis metabolite in surface water and urban wastewater. J Chromatogr A 2009; 1216: 3078-3089.

Booij K, Sleiderink H, Smedes F. Calibrating the uptake kinetics of semipermeable membrane devices using exposure standards. Environ Toxicol Chem 1998; 17: 1236-1245.

Daughton CG. Illicit drugs: Contaminants in the environment and utility in forensic epidemiology. Rev Environ Contam Toxicol 2011; 210: 59-110.

European Monitoring Centre for Drugs and Drug Abuse. Assessing illicit drugs in wastewater: Potential and limitations of a new monitoring approach. EMCDDA, Lisbon, Portugal, 2008.

Garnier J, Laroch L, Pinault S. Determining the domestic specific loads of two wastewater plants of the Paris conurbation (France) with contrasted treatments: a step for exploring the effects of the application of the European Directive. Water Res 2006; 40 (17): 3257-3266.

González-Marino I, Quintana JB, Rodríguez I, Cela R. Determination of drugs of abuse in water by solid-phase extraction, derivatisation and gas chromatography-ion trap-tandem mass spectrometry. J Chromatogr A 2010; 1217: $1748-1760$.

Harman C, Reid M, Thomas KV. Concerning the viewpoint; "An Anti-doping Sampling Strategy Utilizing the Sewerage Systems of Sport Villages”. Environ Sci Technol 2011a; 45: 4191.

Harman C, Reid M, Thomas KV. In situ calibration of a passive sampling device for selected illicit drugs and their metabolites in wastewater, and subsequent year-long assessment of community drug usage. Environ Sci Technol 2011b; 45: 5676-5682. 
Huckins JN, Petty JD, Booij K. Monitors of organic chemicals in the environment - semipermeable membrane devices. Springer, New York, 2006.

Mazzella N, Lissalde S, Moreira S, Delmas F, Mazellier P, Huckins JN. Evaluation of the use of performance reference compounds in an Oasis-HLB adsorbent based passive sampler for improving water concentration estimates of polar herbicides in freshwater. Environ Sci Technol 2010; 44: 1713-1719.

Karolak S, Nefau T, Bailly E, Solgadi A, Levi Y. Estimation of illicit drugs consumption by wastewater analysis in Paris area (France). Forensic Sci Int 2010; 200: 153-160.

Kasprzyk-Hordern B, Dinsdale RM, Guwy AJ. Illicit drugs and pharmaceuticals in the environment - Forensic applications of environmental data. Part 1: Estimation of the usage of drugs in local communities. Environ Pollut 2009; 157: 1773-1777.

Lai FY, Ort C, Gartner C, Carter S, Prichard J, Kirkbride P, Bruno R, Hall W, Eaglesham G, Mueller JF. Refining the estimation of illicit drug consumptions from wastewater analysis: co-analysis of prescription pharmaceuticals and uncertainty assessment. Water Res 2011; 45 (15): 4437-4448.

Mari F, Politi L, Biggeri A, Accetta G, Trignano C, Padua MD, Bertol E. Cocaine and heroin in waste water plants: A 1-year study in the city of Florence, Italy. Forensic Sci Int 2009; 189: 88-92.

Ort C, Lawerance MG, Rieckermann J, Joss A. Sampling for pharmaceuticals and personal care products (PPCPs) and illicit drugs in wastewater systems; Are your conclusions valid? A critical review. Environ Sci Technol 2010; 44: 6024-6035.

Postigo C, de Alda ML Barceló D. Evaluation of drugs of abuse use and trends in a prison through wastewater analysis. Environ Int 2011; 37: 49-55.

Reid MJ, Langford KH, Mørland J, Thomas KV. Quantitative assessment of time dependent drug-use trends by the analysis of drugs and related metabolites in raw sewage. Drug Alcohol Depend 2011; doi:10.1016/ j.drugalcdep.2011.06.007

Reid MJ, Langford KH, Mørland J, Thomas KV. Analysis and interpretation of specific ethanol metabolites, ethyl sulfate, and ethyl glucuronide in sewage effluent for the quantitative measurement of regional alcohol consumption. Alcohol Clin Exp Res 2011; 35: 1593-1599.

Thomas KV, Reid MJ. What else can the analysis of sewage for urinary biomarkers reveal about communities? Environ Sci Technol 2011; doi: 10.1021/es202522d.

van Nuijs ALN, Pecceu B, Theunis L, Dubois N, Charlier C, Jorens PG, Bervoets L, Blust R, Meulemans H, Neels H, Covaci A. Can cocaine use be evaluated through analysis of wastewater? A nation-wide approach conducted in Belgium. Addiction 2009; 104: 734-741.

van Nuijs ALN, Tarcomnicu I, Bervoets L, Blust R, Jorens PG, Neels H, Covaci A. Analysis of drugs of abuse in wastewater by hydrophilic interaction liquid chromatography-tandem mass spectrometry. Anal Bioanal Chem 2009; 395: 819-828.

van Nuijs ALN, Castiglioni S, Tarcomnicu I, Postigo C, Lopez de Alda M, Neels H, Zuccato E, Barcelo D, Covaci A. Illicit drug consumption estimations derived from wastewater analysis: A critical review. Sci Total Environ 2011; 409: 3564-3577.

van Nuijs ALN, Mougel JF, Tarcomnicu I, Bervoets L, Blust R, Jorens PG, Neels H, Covaci A. A one year investigation of the occurrence of illicit drugs in wastewater from Brussels, Belgium. J Environ Monit 2011b; 13: 1008-1016.

van Nuijs ALN, Mougel JF, Tarcomnicu I, Bervoets L, Blust R, Jorens PG, Neels H, Covaci A. Sewage epidemiology - A real-time approach to estimate the consumption of illicit drugs in Brussels, Belgium. Environ Int 2011c; 37: 612-621.

Vrana B, Allan IJ, Greenwood R, Mills GA, Dominiak E, Svensson K, Knutsson J, Morrison G. Passive sampling techniques for monitoring pollutants in water. TrAC Trends Anal Chem 2005; 24: 845-868.

Zuccato E, Chiabrando C, Castiglioni S, Bagnati R, Fanelli R. Estimating community drug abuse by wastewater analysis. Environ Health Perspect 2008; 116: 1027-1032. 